\title{
Comparison of In Vitro Antileukemic Activity of 4-Hydroperoxyifosfamide and 4-Hydroperoxycyclophosphamide
}

\author{
MALGORZATA OPYDO-CHANEK ${ }^{1 *}$, KATARZYNA ŚLADOWSKA ${ }^{1 *}$, KAMIL BLICHARSKI $^{1}$, \\ JAROMIR MIKEŠ ${ }^{2,3}$, PETER FEDOROČKO $^{2}$, ULF NIEMEYER $^{4}$ and LIDIA MAZUR ${ }^{1}$ \\ ${ }^{1}$ Department of Experimental Hematology, Jagiellonian University in Krakow, Krakow, Poland; \\ ${ }^{2}$ Department of Cellular Biology, Pavol Jozef Šafárik University in Košice, Kosice, Slovakia; \\ ${ }^{3}$ Science for Life Laboratory, Karolinska Institute, Stockholm, Sweden; \\ ${ }^{4}$ NIOMECH - IIT GmbH, Bielefeld University, Bielefeld, Germany
}

\begin{abstract}
Background/Aim: The oxazaphosphorines, ifosfamide and cyclophosphamide, represent a class of alkylating agents. The aim of the present in vitro study was to compare antileukemic activity of 4-hydroperoxyifosfamide (4$\mathrm{OOH}-\mathrm{IF}$ ) and 4-hydroperoxycyclophosphamide (4-OOH-CP). Materials and Methods: The experiments were performed on MOLT-4 and ML-1 cells. The research was conducted using flow cytometry fluorescein diacetate/propidium iodide (PI), fluorescein-conjugated annexin V/PI, CaspGLOW Red Active Caspase-8 and -9, CellEvent ${ }^{T M}$ Caspase-3/7 Green assays, and tetramethylrhodamine ethyl ester test. Results: 4-OOH-IF and 4-OOH-CP distinctly reduced cell viability and triggered apoptosis and necrosis, causing changes in intracellular esterase activity, plasma membrane structure and integrity, caspase activation, and mitochondrial membrane potential. The oxazaphosphorines were responsible for the different antileukemic activities. 4-Hydroperoxyifosfamide appeared to be less cytotoxic against the leukemia cells than 4hydroperoxycyclophosphamide. MOLT-4 cells were more sensitive to the action of the oxazaphosphorines than ML-1 cells. Conclusion: The findings provide a new insight on the mechanisms of cytotoxic action of 4-OOH-IF and 4-OOH$C P$ on the human acute lymphoblastic and myeloblastic leukemia cells.
\end{abstract}

\footnotetext{
*These Authors contributed equally to this study.

Correspondence to: Lidia Mazur, Ph.D., D.Sc., Department of Experimental Hematology, Institute of Zoology and Biomedical Research, Jagiellonian University in Krakow, Gronostajowa 9, 30-387 Krakow, Poland. Tel: +48 126645237, Fax: +48 126645101, e-mail: lidia.mazur@uj.edu.pl
}

Key Words: 4-Hydroperoxyifosfamide, 4-hydroperoxycyclophoshamide, cell viability, cell death, in vitro antileukemic activity.
Ifosfamide and cyclophosphamide represent the oxazaphosphorine drugs widely used in clinical practice for their anticancer activity (1-3). Under in vivo conditions, both ifosfamide and cyclophosphamide require metabolic activation by specific hepatic cytochrome enzymes to become therapeutically active (2-4). 4-Hydroperoxyifosfamide (4OOH-IF, D-18851, Figure 1) and 4-hydroperoxycyclophosphamide (4-OOH-CP, D-18864, Figure 1) do not require such metabolic activation in liver and can be applied under in vitro conditions (2).

Cell viability and death are two very important parameters that allow assessment of antileukemic activity of different chemical compounds, e.g. potential anticancer agents $(5,6)$. Cell viability is highly dependent on the processes of regulated death which can be initiated by various extracellular and intracellular stimuli $(7,8)$. Apoptosis and necrosis are two distinct modalities of cell death $(9,10)$ which can be triggered through the two main pathways, namely the extrinsic/receptor, and intrinsic/mitochondrial pathways $(10,11)$. Initiator caspase- 8 and caspase- 9 are important mediators of apoptotic cell death which occurs through the receptor and mitochondrial pathways, respectively, and consequently by executive caspase-3/7 activation (12-15). It is accepted that mitochondria play an essential role during apoptotic and necrotic cell death (1621). According to the recommendations of the Nomenclature Committee on Cell Death, when investigating cytotoxic agents, quantifiable biochemical parameters, such as plasma membrane structure and integrity, activation of caspases, loss of mitochondrial membrane potential, which accompany regulated cell death induced by such agents, should be determined $(8,10,11)$.

The aim of the present study was to compare the in vitro antileukemic activity of 4-hydroperoxyifosfamide and 4-hydroperoxycyclophosphamide. The influence of these oxazaphosphorines on cell viability, and apoptotic and 
necrotic death was evaluated. After application of these agents, the intracellular esterase activity, plasma membrane impairment, phosphatidylserine externalization, caspase-8, 9 , and $-3 / 7$ activity, and loss of mitochondrial membrane potential were analyzed.

\section{Materials and Methods}

Chemicals. 4-Hydroperoxyifosfamide (D-18851, cis-( \pm )-3-(2chloroethyl)-2-((2-chloroethyl)amino) tetrahydro-2-oxide- $2 \mathrm{H}$ 1,3,2-oxazaphosphorine-4-yl-hydroperoxide; 4-OOH-IF) and 4hydroperoxycyclophosphamide (D-18864, cis-( \pm )-2-(bis(2-chloroethyl)amino)tetrahydro-2-oxide- $2 H$-1,3,2-oxazaphosphorine-4-ylhydroperoxide; 4-OOH-CP) (Figure 1) were synthesized at NIOMECH - IIT GmbH (Bielefeld University, Bielefeld, Germany). All solutions were freshly-prepared directly before treatment of cells.

RPMI-1640 medium and fetal calf serum, and Hank's balanced salt solution (HBSS) were obtained from Gibco BRL Life Technologies (Waltham, MA, USA). L-Glutamine, antibiotic antimycotic solution (AAS), and propidium iodide (PI) were purchased from Sigma Aldrich (St. Louis, MO, USA). Fluorescein diacetate (FDA; Sigma Aldrich) and tetramethylrhodamine ethyl ester perchlorate (TMRE; Sigma Aldrich), were kindly provided by the Pavol Jozef Šafárik University in Košice (Košice, Slovakia). Aqua pro injectione and $0.9 \% \mathrm{NaCl}$ were obtained from Polpharma S.A. (Starogard Gdański, Poland), phosphate-buffered saline (PBS) from BioMed (Lublin, Poland), and Hemacolor staining set from Merck KGaA (Darmstadt, Germany). CaspGLOW Red Active Caspase-8 Staining Kit and CaspGLOW Red Active Caspase-9 Staining Kit were purchased from Biovision (Milpiats, CA, USA), and CellEvent ${ }^{\mathrm{TM}}$ Caspase-3/7 Green Flow Cytometry Assay Kit from Molecular Probes (Eugene, OR, USA). Annexin V-FITC Apoptosis Detection Kit were obtained from Becton Dickinson Pharmingen $^{\mathrm{TM}}$ (San Diego, CA, USA).

Leukemia cells. Human acute lymphoblastic leukemia MOLT-4 cells and human acute myeloblastic leukemia ML-1 cells were obtained from the European Collection of Cell Cultures (Salisbury, Wiltshire, UK). MOLT- 4 and ML- 1 cells were cultured in RPMI-1640 medium supplemented with $10 \%$ fetal calf serum, $2 \mathrm{mM}$ L-glutamine, and AAS containing 20 units of penicillin, $20 \mu \mathrm{g}$ streptomycin and 50 ng amphotericin B. The leukemia cells were passaged every third day. MOLT-4 and ML- 1 cells were grown at $37^{\circ} \mathrm{C}$ in an atmosphere of $5 \% \mathrm{CO}_{2}$ in air (HERAcell incubator; KendroLab, Warsaw, Poland). The human acute leukemia cells were seeded in 24-well plates at a density of $15 \times 10^{4}$ before performing each experiment.

Leukemia cell treatment with oxazaphosphorines. After dilution of the cell suspension to a density of $15 \times 10^{4}$ cells $/ \mathrm{ml}$ in complete RPMI-1640 medium, MOLT-4 and ML-1 cells were treated with 4$\mathrm{OOH}-\mathrm{IF}$ and 4-OOH-CP. MOLT-4 cells were exposed to the action of 4-OOH-IF and 4-OOH-CP at the doses of $0.5 \mu \mathrm{g} / \mathrm{ml}, 1 \mu \mathrm{g} / \mathrm{ml}$, and $2.5 \mu \mathrm{g} / \mathrm{ml} \mathrm{medium,} \mathrm{and} \mathrm{ML-1} \mathrm{cells} \mathrm{were} \mathrm{treated} \mathrm{with} \mathrm{these}$ agents at the doses of $1 \mu \mathrm{g} / \mathrm{ml}, 5 \mu \mathrm{g} / \mathrm{ml}$, and $10 \mu \mathrm{g} / \mathrm{ml} \mathrm{medium}$. The doses of oxazaphosphorines used in the present studies were based on the unpublished data. 4-OOH-IF and 4-OOH-CP were dissolved in aqua pro injectione directly before application. The control consisted of untreated MOLT- 4 and ML-1 cells.
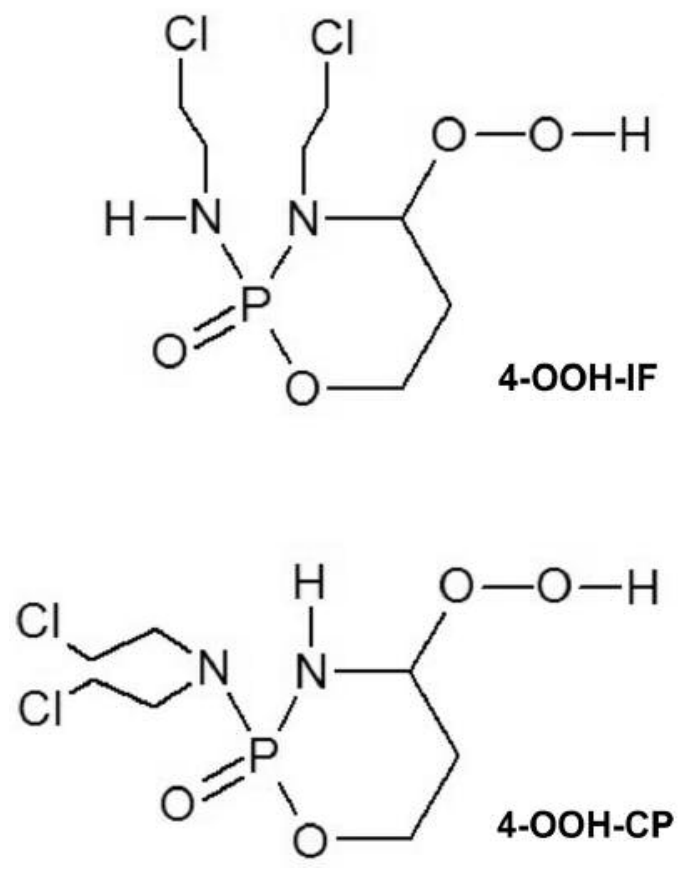

Figure 1. Chemical structures of 4-hydroperoxyifosfamide (D-18851, 4-OOH-IF) and 4-hydroperoxycyclophosphamide (D-18864, 4-OOH-CP).

Analyses of human leukemia cells exposed to 4-OOH-IF and 4$O O H-C P$. The changes occurring in MOLT- 4 and ML-1 cells after application of 4-OOH-IF and 4-OOH-CP, were determined using flow cytometry FDA/PI, annexin V-FITC/PI, CaspGLOW Red Active Caspase- 8 and -9 , CellEvent ${ }^{\mathrm{TM}}$ Caspase-3/7 Green, and TMRE assays.

Flow cytometric FDA/PI assay. Using the FDA/PI assay, FDA is taken up by live cells and hydrolyzed by intracellular esterases, and PI is excluded by an intact cell membrane. Briefly, the leukemia cell suspension containing $5 \times 10^{5}$ cells was centrifuged for $7 \mathrm{~min}$ at $100 \times \mathrm{g}$ and $37^{\circ} \mathrm{C}(\mathrm{MPW}-351 \mathrm{RH}$ centrifuge; Med. Instruments, Warszawa, Poland), and the cell pellet was resuspended in $1 \mathrm{ml}$ of warm HBSS. Then, $10 \mu \mathrm{l}$ of FDA working solution, at a concentration of $1 \mu \mathrm{g} / \mathrm{ml}$ in HBSS, was added and the leukemia cells were incubated in the dark for $15 \mathrm{~min}$ at $37^{\circ} \mathrm{C}$. After the incubation with FDA, $20 \mu$ of PI working solution, at a concentration of $30 \mu \mathrm{g} / \mathrm{ml}$ in $0.9 \% \mathrm{NaCl}$, was added, and the cells were incubated for additional $5 \mathrm{~min}$. Incubation of cells in the presence of both FDA and PI labeled live cells as green, and cells with impaired plasma membrane integrity as red. Cell samples were placed on ice, away from light, and FDA and PI was immediately measured using flow cytometry (Becton Dickinson, San Jose, CA, USA).

Flow cytometric annexin V-FITC/PI assay. Using Annexin VFITC Apoptosis Detection Kit, the procedure of dual staining of cells was performed. Briefly, leukemia cell suspension containing $5 \times 10^{5}$ cells was washed twice with cold PBS, the cells were centrifuged for $7 \mathrm{~min}$ at $100 \times g$ and $4^{\circ} \mathrm{C}(\mathrm{MPW}-351 \mathrm{RH}$ 
A
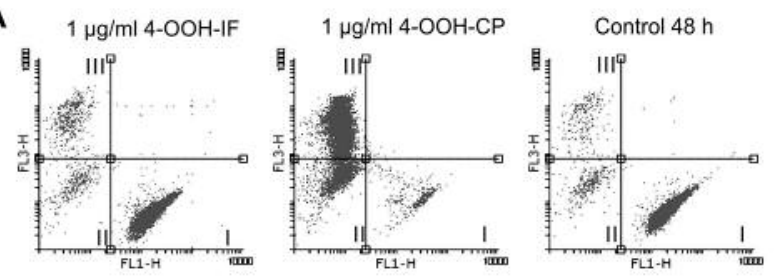

MOLT-4
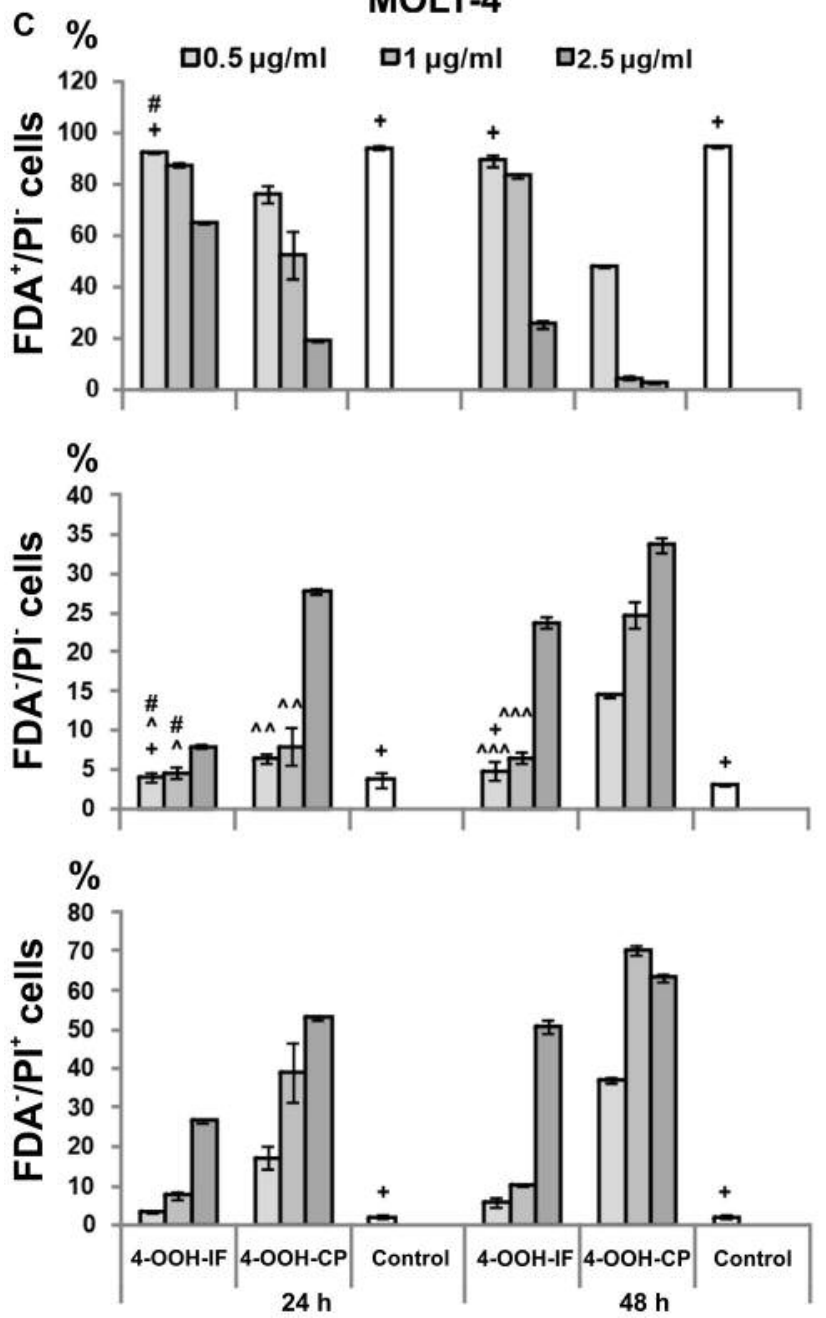
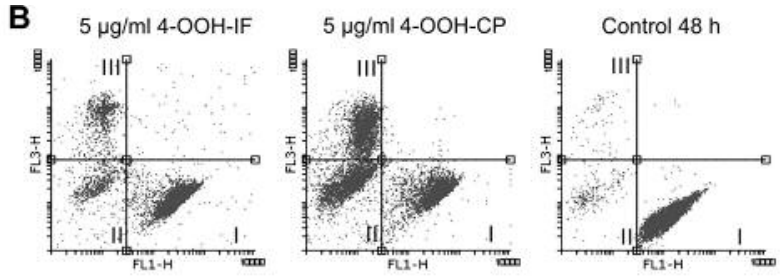

ML-1
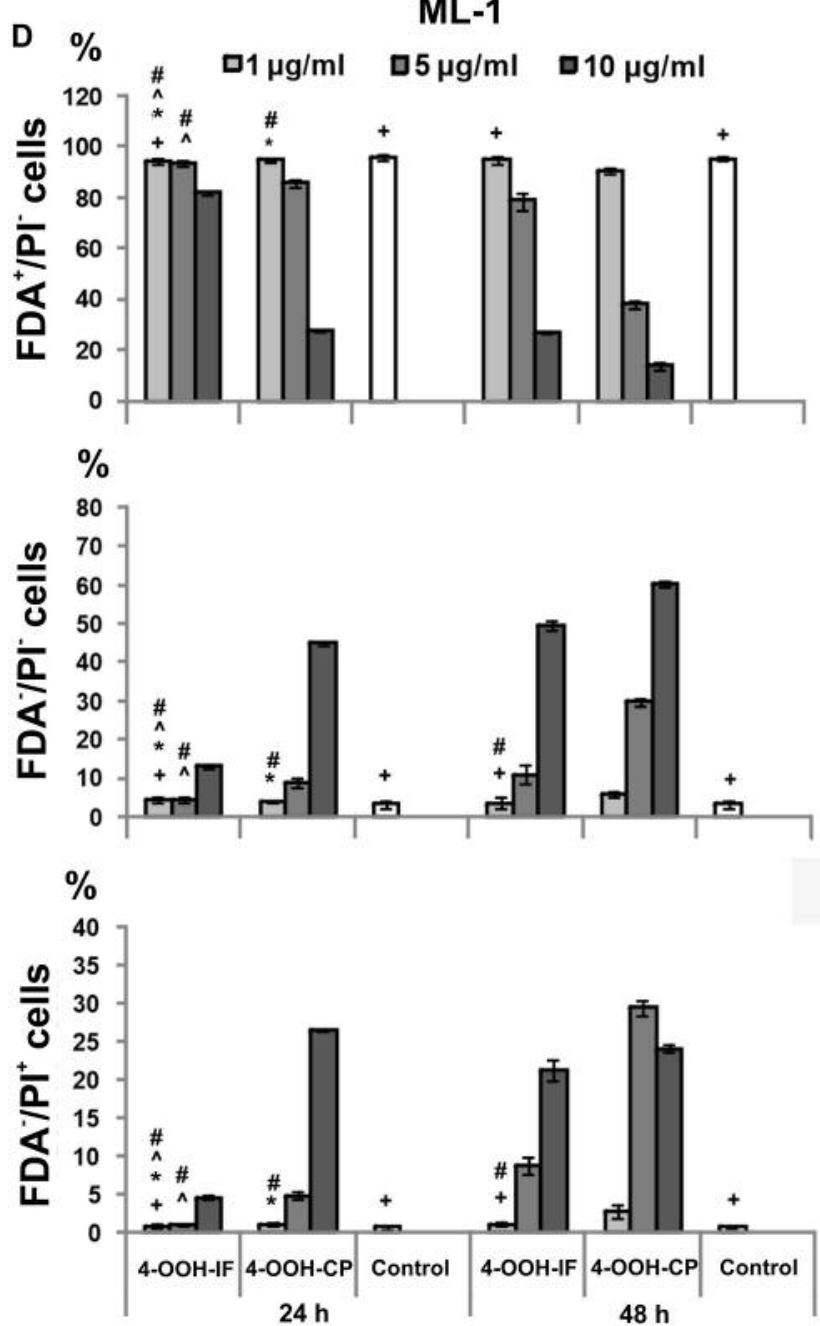

Figure 2. Effects of 4-hydroperoxyifosfamide (4-OOH-IF) and 4-hydroperoxycyclophosphamide (4-OOH-CP) on the viability of MOLT-4 and ML-1 cells determined by flow cytometric fluorescein diacetate (FDA)/propidium iodide (PI) assay. Representative dot plots for MOLT-4 (A) and ML-1 (B) cells stained with FDA (FL1-H) and PI (FL3-H) observed 48 h after application of oxazaphosphorines. Three leukemia cell populations were distinguished: (I) $F D A^{+} / P^{-}$, (II) $F D A^{-} / P I^{-}$, and (III) $F D A^{-} / P I^{+}$. The percentage values of the different cell populations of MOLT-4 (C) and $M L-1(D)$ cells were determined $24 \mathrm{~h}$ and $48 \mathrm{~h}$ after application of 4-OOH-IF and 4-OOH-CP. The obtained data are presented as mean values \pm SD, calculated from three independent experiments carried out in triplicate. Values not significantly different at $p<0.05$ according to Tukey's multiple range test: \#compared to controls; $\wedge$ between the same agent at different doses; *between agents at the same dose; +between time points.

centrifuge; Med. Instruments), and resuspended in $100 \mu \mathrm{l}$ of cold binding buffer. Then $2.5 \mu \mathrm{l}$ of annexin V-FITC and $2.5 \mu \mathrm{l}$ of PI staining solution were added and the cells were incubated in the dark for $15 \mathrm{~min}$ at room temperature. Following the incubation,
$400 \mu \mathrm{l}$ of binding buffer was added to each tube. Cell samples were placed on ice, away from light, and FITC and PI fluorescence was immediately measured using flow cytometry (Becton Dickinson). 

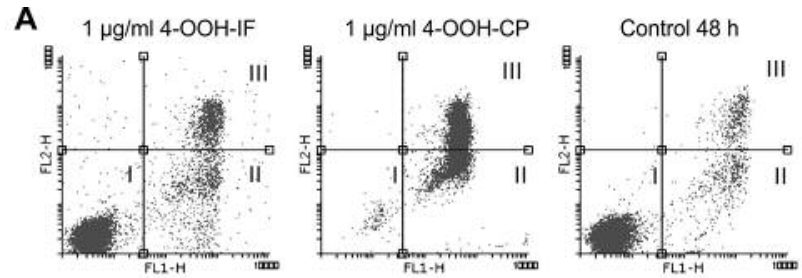

MOLT-4

C

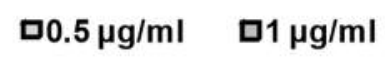

$\square 2.5 \mu \mathrm{g} / \mathrm{ml}$
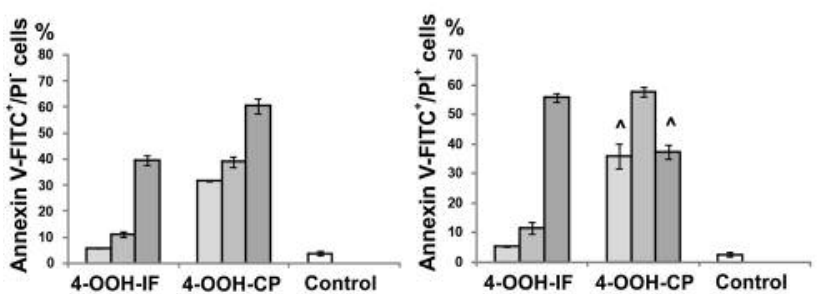
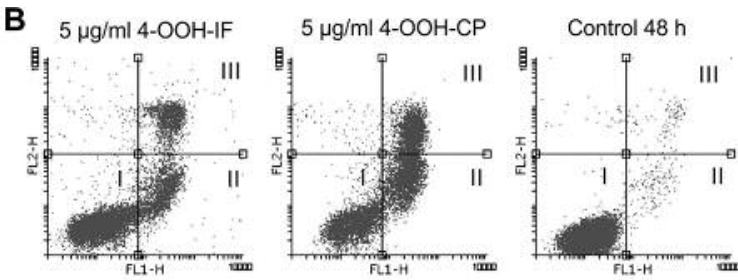

ML-1

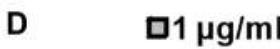

$\square 5 \mu \mathrm{g} / \mathrm{ml}$

口10 $\mu \mathrm{g} / \mathrm{ml}$
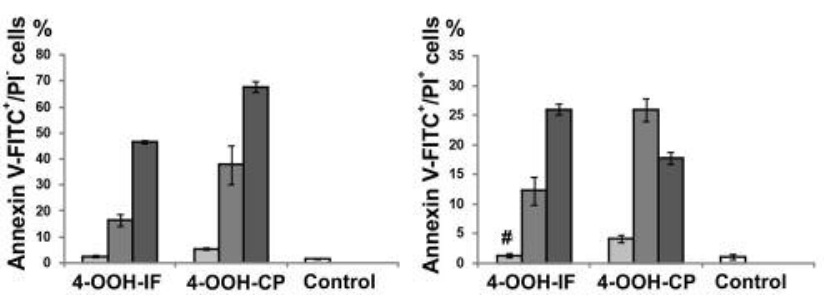

Figure 3. Effects of 4-hydroperoxyifosfamide (4-OOH-IF) and 4-hydroperoxycyclophosphamide (4-OOH-CP) on apoptotic and necrotic death of MOLT-4 and ML-1 cells determined by flow cytometric annexin V-fluorescein isothiocyanate (FITC)/propidium iodide (PI) assay. Representative dot plots for MOLT-4 (A) and ML-1 (B) cells obtained $48 \mathrm{~h}$ after application of the oxazaphosphorines; FL1-H: green fluorescence of FITC, FL2-H: red fluorescence of PI. Based on the plasma membrane diversity and impairment, the populations of live cells (I, annexin V-FITC-/PI-), early apoptotic cells (II, annexin $\mathrm{V}$-FITC $\left.{ }^{+} / \mathrm{PI}^{-}\right)$, and late apoptotic and necrotic cells (III, annexin $\left.\mathrm{V}-\mathrm{FITC}^{+} / \mathrm{PI}^{+}\right)$were distinguished. The percentage of annexin V-FITC ${ }^{+} / P^{-}$and annexin V-FITC ${ }^{+} / P^{+}$MOLT-4 $(C)$ and $M L-1$ (D) cells was determined 48 h after application of the tested oxazaphosphorine agents. The data are presented as the mean $\pm S D$ calculated from three independent experiments carried out in duplicate. Values not significantly different at $p<0.05$ according to the Tukey's multiple range test: ${ }^{*}$ compared to controls; ${ }^{\wedge}$ between the same agent at different doses.

Flow cytometric caspase- 8 and -9 assays. Cells were analyzed using CaspGLOW Red Active Caspase-8 Staining Kit and CaspGLOW Red Active Caspase-9 Staining Kit. The fluorescent markers, caspase-8 inhibitor IETD-fluoromethylketone conjugated to sulforhodamine (Red-IETD-FMK), and caspase-9 inhibitor LEHDfluoromethylketone conjugated to sulfo-rhodamine (Red-LEHDFMK), irreversibly bind, respectively, to caspase- 8 and caspase- 9 activated in apoptotic cells. Briefly, the cell suspension was centrifuged for $7 \mathrm{~min}$ at $100 \times g$ and $37^{\circ} \mathrm{C}$ (MPW-351RH; Med. Instruments), and the supernatant was removed by aspiration. The cell pellet was resuspended in $150 \mu \mathrm{l}$ of PBS, and $0.5 \mu \mathrm{l}$ of RedIETD-FMK or $0.5 \mu \mathrm{l}$ of Red-LEHD-FMK was added into each sample, and the cells were incubated for $1 \mathrm{~h}$ at $37^{\circ} \mathrm{C}$. Then the cell suspension was centrifuged, the supernatant was removed, and the cells were washed twice in $500 \mu \mathrm{l}$ of wash buffer. After the washing step, the cells were resuspended in $300 \mu$ of wash buffer, put on ice and analyzed using flow cytometry (Becton Dickinson).

Flow cytometry caspase-3/7 assay. Cells were analyzed using CellEvent $^{\mathrm{TM}}$ Caspase-3/7 Green Flow Cytometry Assay Kit. CellEvent $^{\mathrm{TM}}$ Caspase-3/7 Green Detection Reagent, a fluorogenic substrate for activated caspases-3 and -7 , consisting of a four-amino acid peptide (DEVD) is conjugated to a nucleic acid-binding dye. After activation of caspase-3/7 in apoptotic cells, DEVD peptide is cleaved, enabling the dye to bind to DNA and producing a bright, fluorogenic response. Briefly, the cell suspension was centrifuged for $7 \mathrm{~min}$ at $100 \times g$ and $37^{\circ} \mathrm{C}$ (MPW $351 \mathrm{RH}$; Med. Instruments) and the supernatant was removed by aspiration. The cell pellet was resuspended in $500 \mu \mathrm{l}$ of PBS. Then $0.5 \mu \mathrm{l}$ of CellEvent ${ }^{\mathrm{TM}}$ Caspase3/7 Green Detection Reagent was added to each sample and the cells were incubated for $30 \mathrm{~min}$ at $37^{\circ} \mathrm{C}$. After incubation, the leukemia cell samples were analyzed by flow cytometry (Becton Dickinson).

Flow cytometric analysis of mitochondrial membrane potential $(M M P)$. The MMP was analyzed by means of the lipophilic cationic dye TMRE. Retention of TMRE, cell-permeable, positively-charged, red-orange dye, depends on MMP - more greatly polarized mitochondria accumulate more cationic dye, while depolarized mitochondria accumulate less dye. A TMRE stock solution was prepared at a concentration of $10 \mathrm{mM}$ in dimethyl sulfoxide and stored at $-20^{\circ} \mathrm{C}$. The final concentration of TMRE staining solution used was $100 \mathrm{nM}$. Briefly, the leukemia cell suspension containing $2.5-5 \times 10^{5}$ cells $/ \mathrm{ml}$ was centrifuged for $7 \mathrm{~min}$ at $100 \times g$ and $37^{\circ} \mathrm{C}$ (MPW-351RH; Med. Instruments). The cell pellet was then washed twice in $1 \mathrm{ml}$ of warm HBSS, resuspended in $100 \mu \mathrm{l}$ of $100 \mathrm{nM}$ TMRE, and incubated at $37^{\circ} \mathrm{C}$ in the darkness. After 20-min incubation, the cells were washed with $1 \mathrm{ml}$ of warm HBSS and centrifuged. Next, the supernatant was discarded and the cells were resuspended in $500 \mu \mathrm{l}$ of HBSS. TMRE fluorescence was immediately detected by flow cytometry (Becton Dickinson).

Statistical evaluation. All flow cytometric data were analyzed using Flowing Software version 2.5.1 (Perttu Terho, Turku Centre of Biotechnology, University of Turku, Finland). The statistical 
A

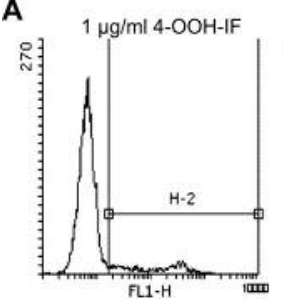

C $\%$

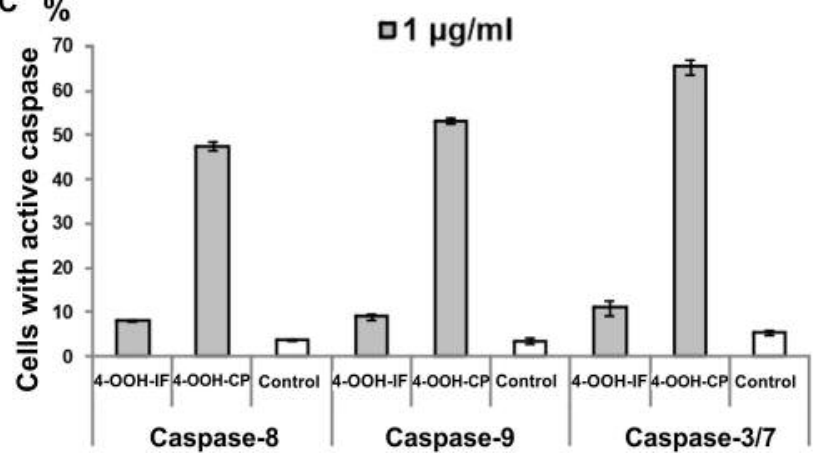

B
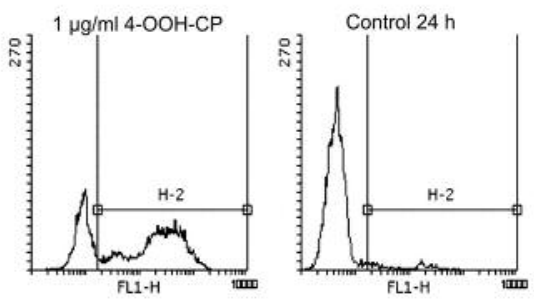

MOLT-4

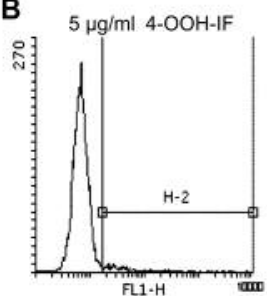

D $\%$

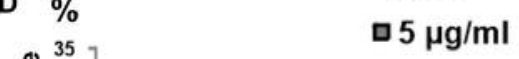

ML-1
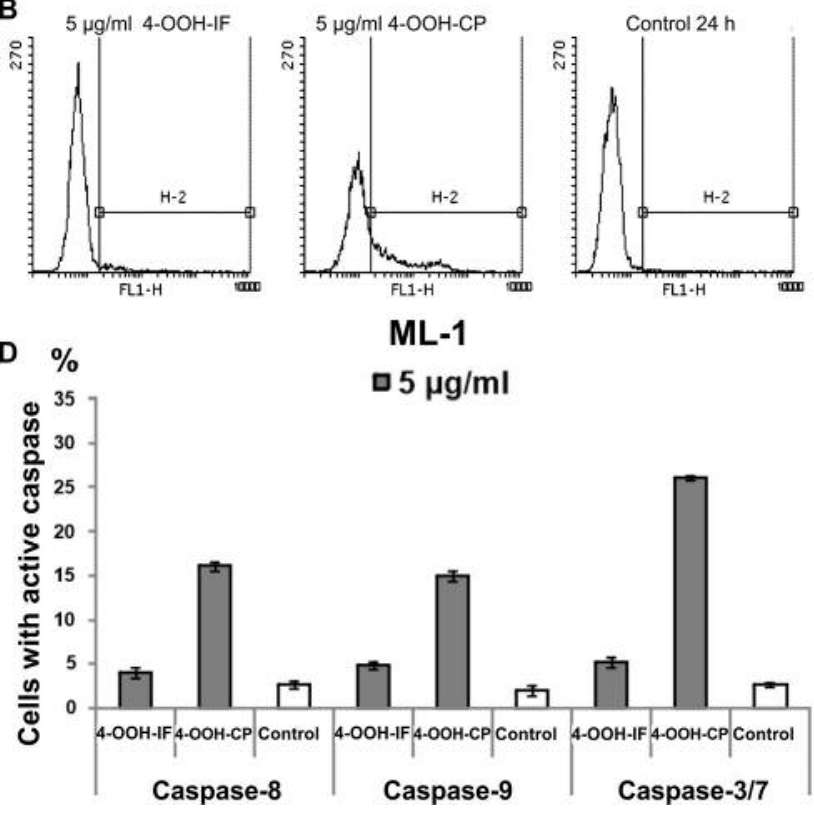

Figure 4. Flow cytometric analysis of MOLT-4 and ML-1 cells with active caspase-8, -9, and -3/7, conducted 24 h after application of 4-hydroperoxyifosfamide (4-OOH-IF) and 4-hydroperoxycyclophosphamide (4-OOH-CP). Representative histograms of MOLT-4 (A) and ML-1 (B) cells obtained after their exposure to the action of 4-OOH-IF and 4-OOH-CP; H-2: cells with active caspase-3/7; FL1-H: CellEvent ${ }^{T M}$ Caspase3/7 Green fluorescence. The percentage of MOLT-4 (C) and ML-1 (D) cells with active caspase-8, -9, and -3/7 was determined $24 \mathrm{~h}$ after their exposure to the action of 4-OOH-IF and 4-OOH-CP. The data are presented was the mean \pm SD calculated from three independent experiments carried out in duplicate. All data differed significantly at $p<0.05$ according to Tukey's multiple range test.

significance for the data was evaluated by STATISTICA 10 (StatSoft, Krakow, Poland) using one-way analysis of variance followed by Tukey's honestly significant differences multiple range test. A difference with $p<0.05$ was considered statistically significant.

\section{Results}

The influence of two oxazaphosphorine agents, 4-OOH-IF and $4-\mathrm{OOH}-\mathrm{CP}$, on alterations in the frequency of three leukemia cell populations $\mathrm{FDA}^{+} / \mathrm{PI}^{-}, \mathrm{FDA}^{-} / \mathrm{PI}^{-}$, and $\mathrm{FDA}^{-} / \mathrm{PI}^{+}$(Figure 2), the percentage values of both annexin $\mathrm{V}-\mathrm{FITC}^{+} / \mathrm{PI}^{-}$cells and annexin $\mathrm{V}-\mathrm{FITC}^{+} / \mathrm{PI}^{+}$cells (Figure 3 ), as well as in the frequency of cells with active caspase-8, -9, and $-3 / 7$ (Figure 4) and cells with dissipated MMP (Figure 5) were determined. The cytotoxic activity of the oxazaphosphorines depended on the agent tested, its dose, and the leukemia cell line used (Figures 2-5). 4-OOH-CP reduced leukemia cell viability (Figure 2), triggered apoptotic and necrotic cell death (Figure 3), promoted caspase activity (Figure 4), and caused the loss of MMP (Figure 5) to a higher degree than did 4-OOH-IF. The oxazaphosphorine agents led to weaker cytotoxic effects in ML-1 cells than in MOLT-4 cells (Figure 2-5).

\section{Discussion}

In the present study, the in vitro cytotoxic activity of 4-OOHIF and 4-OOH-CP against human acute lymphoblastic leukemia MOLT-4 cells and human acute myeloblastic leukemia ML-1 cells was compared. After application of the oxazaphosphorines, various patterns of changes in intracellular esterase activity, plasma membrane integrity and cell surface exposure of phosphatidylserine, caspase-8, -9, and $-3 / 7$ activation, and the MMP were found in MOLT-4 and ML-1 cells. In general, 4-OOH-IF appeared to be less cytotoxic than 4-OOH-CP against the human acute leukemia cells, and MOLT cells were more sensitive than ML-1 cells to the action of both oxazaphosphorine agents.

The mechanisms of action of 4-OOH-IF and 4-OOH-CP depend on their chemical structure and metabolism. The oxazaphosphorine structure is composed of an oxazaphosphorin-2-amine 2-oxide heterocycle containing one atom of phosphorus, one atom of nitrogen and one of oxygen. Ifosfamide and cyclophosphamide have an isomeric structure with one or two 2-chloroethyl groups linked to the nitrogen, respectively $(2,3)$. In aqueous solution, 4-OOHIF and 4-OOH-CP spontaneously and rapidly generate 4- 

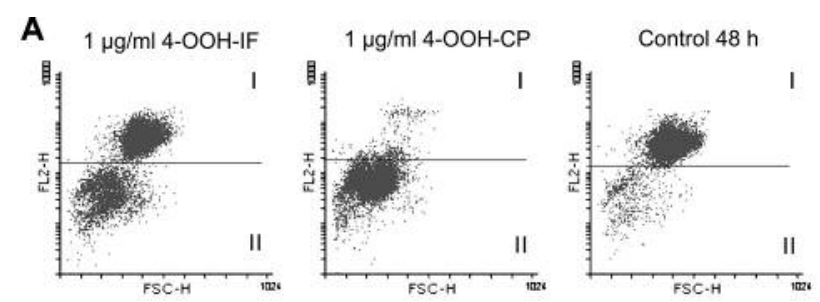

MOLT-4

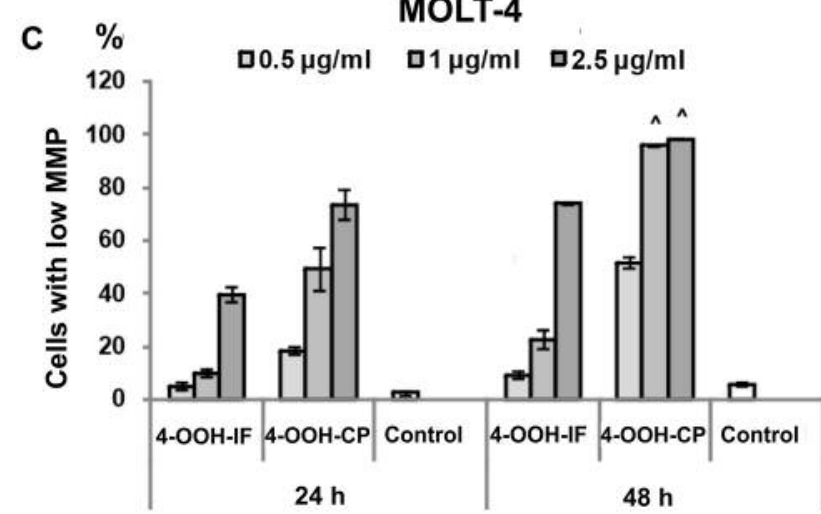

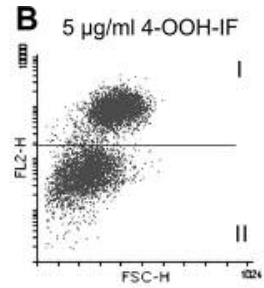
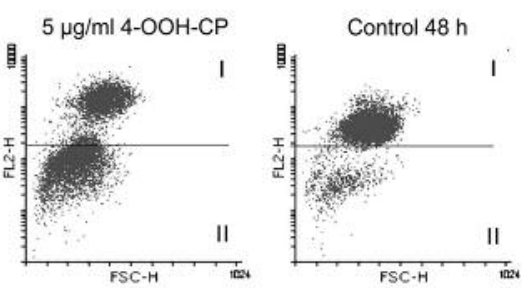

ML-1

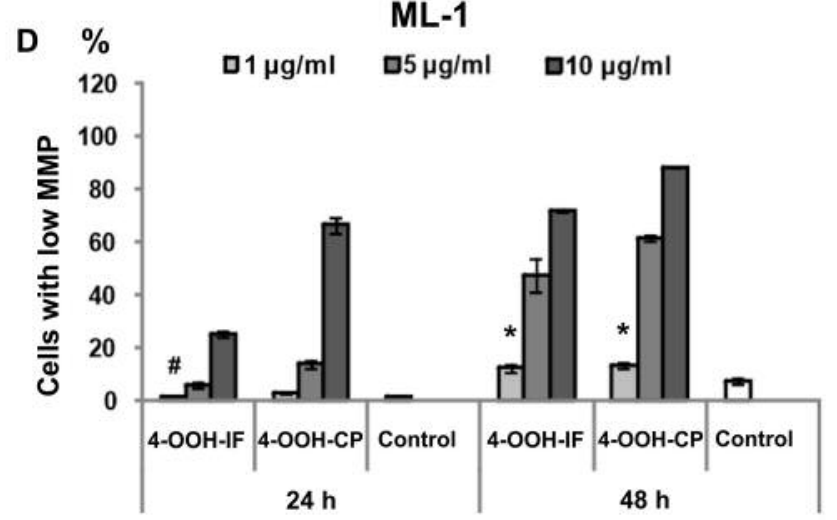

Figure 5. Effects of 4-hydroperoxyifosfamide (4-OOH-IF) and 4-hydroperoxycyclophosphamide (4-OOH-CP) on changes in mitochondrial membrane potential (MMP) of MOLT-4 and ML-1 cells. Representative dot plots for MOLT-4 (A) and ML-1 (B) cells obtained 48 h after their exposure to the action of the two oxazaphosphorines using flow cytometric test; I: cells with high MMP, II: cells with low MMP. The percentage of MOLT-4 (C) and ML-1 (D) cells with low MMP observed $24 \mathrm{~h}$ and $48 \mathrm{~h}$ after application of the tested oxazaphosphorine agents. The data are presented as the mean $\pm S D$ calculated from three independent experiments carried out in triplicate. Values not significantly different at p<0.05 according to the Tukey's multiple range test: " compared to controls; ^between the same agent at different doses; *between different agents at the same dose.

hydroxyifosfamide (4-OH-IF) and 4-hydroxycyclophosphamide (4-OH-CP), respectively, moreover both agents additionally generate HO-radicals and hydrogen peroxide. 4-OH-IF degrades via aldoifosfamide to ifosfamide mustard and acrolein, while 4-OH-CP degrades via aldophosphamide to phosphoramide mustard and acrolein. It is accepted that ifosfamide mustard and phosphoramide mustard are the major reactive alkylating agents of 4-OOH-IF and 4-OOH-CP. The cytotoxic effects of these mustard agents result from intermolecular, alkylation or bisalkylation reactions relating to the intermediate electrophilic aziridinyl species. The reactive alkylating compounds are involved in cytotoxic reactions because they can bind to a variety of cellular molecules disturbing normal processes occurring in the cell (1-3).

The present findings indicate that the action of 4-OOHIF and 4-OOH-CP resulted in induction of apoptosis and necrosis. In human acute leukemia cells undergoing regulated death, 4-OOH-IF and 4-OOH-CP caused plasma membrane impairment and loss of its phospholipid asymmetry by phosphatidylserine externalization, as well as mitochondrial dysfunction. Moreover, these oxazaphosphorines triggered caspase-dependent apoptosis through the receptor and mitochondrial pathways by caspase-8, -9, and $-3 / 7$ cascade activation. These are the first data comparing the regulated cell death-inducing potential of 4$\mathrm{OOH}-\mathrm{IF}$ and 4-OOH-CP in human acute lymphoblastic and myeloblastic leukemia cells.

\section{Conclusion}

To summarize, the varied responses of MOLT-4 and ML-1 cells to the action of 4-OOH-IF and 4-OOH-CP depend on the chemical structure of the agent and the cell line status. The different in vitro antileukemic activities of these oxazaphosphorine agents are associated with their potential for triggering regulated cell death, which is accepted to be one of the mechanisms of cancer therapy. Understanding the processes of regulated cell death induced by oxazaphosphorines is of key importance in chemotherapy.

\section{Conflicts of Interest}

The Authors declare that there are no conflicts of interest in regard to this study. 


\section{Acknowledgements}

The Authors are very grateful to Ms. Urszula Kłaput for her excellent technical assistance. The study was supported by the Research Projects K/ZDS/004835 and K/ZDS/005415.

\section{References}

1 Liang J, Huang M, Duan W, Yu X and Zhou S: Design of new oxazaphosphorine anticancer drugs. Curr Pharm Des 13: 963 978, 2007.

2 Giraud B, Hebert G, Deroussent A, Veal GJ, Vassal G and Paci A: Oxazaphosphorines: new therapeutic strategies for an old class of drugs. Expert Opin Drug Metab Toxicol 6: 919-938, 2010.

3 Sloderbach A, Górska A, Sikorska M, Misiura K and Hładoń B: Klasyczne oksazafosforinany - metabolizm i właściwości terapeutyczne. Clasical oxazaphosphorines - metabolism and therapeutic properties. Postepy Hig Med Dosw 67: 1235-1253, 2013 (In Polish).

4 Zhang J, Tian Q, Yung Chan S, Chuen Li S, Zhou S, Duan W and Zhu YZ: Metabolism and transport of oxazaphosphorines and the clinical implications. Drug Metab Rev 37: 611-703, 2005.

5 Opydo-Chanek $\mathrm{M}$ and Mazur L: Comparison of in vitro antileukemic activity of obatoclax and ABT-737. Tumor Biol 37: 10839-10849, 2016.

6 Śladowska K, Handzlik J, Kieć-Kononowicz K and Mazur L: In vitro cytotoxic activity evaluation of phenytoin derivatives against human leukemia cells. Ind J Exp Biol 54: 553-559, 2016.

7 Henriquez M, Armisen R, Stutzin A and Quest AFG: Cell death by necrosis, a regulated way to go. Curr Mol Med 8: 187-206, 2008.

8 Galluzzi L, Bravo-San Pedro JM, Vitale I, Aaronson SA, Abrams JM, Adam D, Alnemri ES, Altucci L, Andrews D, AnnicchiaricoPetruzzelli M, Baehrecke EH, Bazan NG, Bertrand MJ, Bianchi $\mathrm{K}$, Blagosklonny MV, Blomgren K, Borner C, Bredesen DE, Brenner C, Campanella M, Candi E, Cecconi F, Chan FK, Chandel NS, Cheng EH, Chipuk JE, Cidlowski JA, Ciechanover A, Dawson TM, Dawson VL, De Laurenzi V, De Maria R, Debatin K-M, Di Daniele N, Dixit VM, Dynlacht BD, El-Deiry WS, Fimia GM, Flavell RA, Fulda S, Garrido C, Gougeon ML, Green DR, Gronemeyer H, Hajnoczky G, Hardwick JM, Hengartner MO, Ichijo H, Joseph B, Jost PJ, Kaufmann T, Kepp O, Klionsky DJ, Knight RA, Kumar S, Lemasters JJ, Levine B, Linkermann A, Lipton SA, Lockshin RA, López-Otín C, Luglli E, Madeo F, Malorni W, Marine J-C, Martin SJ, Martinou J-C, Medema JP, Meier P, Melino S, Mizuhima N, Moll U, MuñouzPinedo C, Nuñez G, Oberst A, Panaretakis T, Penninger JM, Peter ME, Piacentini M, Pinton P, Prehn JH, Puthalakath H, Rabinovich GA, Ravichandran KS, Rizzuto R, Rodrigues CM, Rubinsztein DC, Rudel T, Shi Y, Simon H-U, Stockwell BR, Szabadkai G, Tait SW, Tang HL, Tavernarakis N, Tsujimoto Y, Vanden Berghe T, Vandenabeele P, Villunger A, Wagner EF, Walczak H, White E, Wood WG, Yuan J, Zakeri Z, Zhivotovsy B, Melino G and Kroemer G: Essential versus accessory aspects of cell death: recommendations of the NCCD. Cell Death Differ 22: 58-73, 2015.
9 Tsuimoto Y: Apoptosis and necrosis: intracellular ATP level as a determinant for cell death modes. Cell Death Differ 4: 429-434, 1997.

10 Kroemer G, Galluzzi L, Vandenabeele P, Abrams J, Alnemri ES, Baehrecke EH, Blagosklonny MV, El-Deiry WS, Golstein P, Green DR, Hengartner M, Knight RA, Kumar S, Lipton SA, Malorni W, Nuñez G, Peter ME, Tschopp J, Yuan J, Piacentini M, Zhivotovsky B and Melino G: Classification of cell death: recommendations of the Nomenclature Committee on Cell Death 2009. Cell Death Differ 16: 3-11, 2009.

11 Galluzzi L, Vitale I, Abrams JM, Alnemri ES, Baehrecke EH, Blagosklonny MV, Dawson TM, Dawson VL, El-Deiry WS, Fulda S, Gottlieb E, Green DR, Hengartner MO, Kepp O, Knight RA, Kumar S, Lipton SA, Lu X, Madeo F, Malorni W, Mehlen P, Nuñez G, Peter ME, Piacentini M, Rubinsztein DC, Shi Y, Simon H-U, Vandenabeele P, White E, Yuan J, Zhivotovsky B, Melino G and Kroemer G: Molecular definitions of cell death subroutines: recommendations of the Nomenclature Committee on Cell Death. Cell Death Differ 19: 107-120, 2012.

12 Nuñez G, Benedict MA, Hu Y and Inohara M: Caspases: the proteases of apoptotic pathway. Oncogene 17: 3237-3245, 1998.

13 Creag EM and Martin SJ: Caspases: cellular demolition experts. Biochem Soc Trans 29: 696-702, 2001.

$14 \mathrm{Li} \mathrm{J}$ and Yuan J: Caspases in apoptosis and beyond. Oncogene 27: 6194-6206, 2008.

15 Mcllwain DR, Berger T and Mak TW: Caspase functions in cell death and disease. Cold Spring Harb Perspect Biol 5: 1-28, 2013.

16 Kroemer G, Dallaporta B and Resche-Rigon M: The mitochondrial death/life regulator in apoptosis and necrosis. Annu Rev Physiol 60: 619-642, 1998.

17 Desagher S and Martinou J: Mitochondria as the central point of apoptosis. Trends Cell Biol 10: 369-377, 2000.

18 Gotlieb RA: Mitochondria: execution central. FEBS Lett 482: 612, 2000.

19 Lee HC and Wei H: Mitochondrial role in life and death of the cell. J Biomed Sci 7: 2-15, 2000.

20 Halestrap AP, Doran E, Gillespie JP and Oyule A: Mitochondria and cell death. Biochem Soc Trans 28: 170-177, 2001.

21 Borutaite V: Mitochondria as decision-makers in cell death. Environ Mol Mutagen 51: 406-416, 2010.
Received August 5, 2017

Revised September 9, 2017 Accepted September 19, 2017 